\title{
A COMUNICAÇÃO ENTRE CORPOS E METRÓPOLES
}

\section{Communication between bodies and metropolis}

\author{
Massimo Canevacci ${ }^{1}$
}

\begin{abstract}
Resumo
Este artigo discute as novas formas de manifestação da interação, comunicação, entre os indivíduos no contexto das metrópoles contemporâneas. São apresentadas as influências da comunicação digital neste processo. Discute-se o papel do consumo, as manifestações do corpo e percebe-se que o indivíduo dá lugar hoje ao que se pode denominar de multivíduo da metrópole comunicacional, cuja alternativa de compreensão, dá-se a partir de métodos polifônicos.
\end{abstract}

Palavras-chave: metrópoles, consumo performático, body-corpse, multivíduo, métodos polifônico.

\begin{abstract}
This article discusses the new manifestions of interaction, communication, among people in contemporary context of metropolis. We present the influences of digital communication in this process. We think about consumption, the body manifestations and we can note that individual concept has been changed by the concept of multividual in the communicational metropolis. So to understand these news occurrences we work with polifonics methods. Keyword: metropolis, performatic consumption; body-corpse, multividual, polifonic methods.
\end{abstract}

\section{Resumen}

Este artículo traenos la discusión sobre las nuevas formas de manifestación de la interaccíon, communicación, entre los indiviuos en el contexto de las metrópoles contemporaneas. Son presentadas las influencias de la communicación digital em este proceso. Discutese tambien el role del consumo, las manifestaciones del cuerpo y percebese que el indiviuo hoy dá lugar al que se puede llamar de multividuo de la metrópole communicacional, cuya alternativa de investigación dáse a partir de los métodos polifónicos.

\footnotetext{
${ }^{1}$ Professor de Antropologia Cultural na Faculdade de Ciências da Comunicação na Universidade La Sapienza de Roma, Itália. Editor da Revista Avatar.
} 
Palavras-clave: metrópoles, consumo performático, body-corpse, multividuo, métodos polifónicos.

\section{COMUNICAÇÃO DIGITAL}

A diferença fundamental entre a comunicação analógica e a comunicação digital é que a primeira fundamenta-se na dimensão do coletivo, mesmo que não seja tão simples precisar esse coletivo. Na comunicação digital são as dimensões do conectivo que estão em evidência e que acabam por caracterizar esse processo, diferenciando-o. Isto significa que a dimensão sociopolítica do coletivo, que assume e politiza o ser humano na sua individualidade, perdeu sua característica decisiva; na modernidade industrializada é que estabelecemos, mesmo que parcialmente, nosso destino: tentar mudar o sistema dominante. Mas como se realizou historicamente essa busca, é claríssimo que nunca funcionou de maneira adequada. Então, a cultura e a comunicação digital, que colocam em crise esta perspectiva coletiva, conseguem afirmar o processo conectivo que significa que a individualidade, que prefiro chamar de multivíduo se multiplica, se amplia, explode. Uma multiplicidade de eus no corpo subjetivo. Essa condição múltipla favorece a proliferação dos eus o que acaba por desenvolver outro tipo de identidade, fluida e pluralizada, que coloca, potencialmente em crise, as formas perversas e tradicionais do dualismo.

Conectividade significa que o individuo, nas suas fluidas dimensões dos seus eus, possa conectar-se com diferentes espaços-tempos no mesmo momento, junto com pessoas totalmente diferenciadas. O que configura um cronotopo polifônico e híbrido denso de potencialidade libertadora. Tudo isso significa que a política, no seu sentido mais preciso, está mudando profundamente. Significa que as formas contemporâneas das políticas têm de incorporar a comunicação digital como constituinte de uma nova cidadania. Uma cidadania não mais determinada pelo estado-nação, mas flutuante entre e-spaces (espaços eletrônicos - material e imaterial) que nos interconecta com fragmentos das metrópoles comunicacionais. Claramente, tudo isso se refere também e, quiçá especialmente, aos jovens: as culturas - não apenas as culturas eXtremas (Canevacci 2005), mas também as culturas pluralizadas e, felizmente, fragmentadas das juventudes atuais que buscam se desenvolver, criar e aplicar a cultura digital como parte fundamental de sua subjetividade.

\section{METRÓPOLE COMUNICACIONAL}


O processo que se iniciou mais ou menos nos anos 70, não é possível precisar uma data exata, no mundo ocidental, mas não apenas, foi a transição da cidade industrial para o que chamamos de metrópole comunicacional. Isto é, a cidade industrial tinha como monumento central a fábrica. A fábrica era o local, não somente da produção econômica, de valor, mas também o lugar de uma vigorosa produção política. Era o centro do conflito, das tensões. Era também o contexto que desenvolveu a forma mais poderosa de lógica, isto é, a dialética. Era ainda o espaço privilegiado de formação dos partidos. Nesse aspecto, a fábrica dava o sentido da transformação não somente econômica, como cultural e sociológica da cidade. Naquela época dava para entender a cidade a partir do entendimento do que era a produção industrial. Porém, nos últimos 30 anos aconteceu um processo, que vem ocorrendo lentamente, e que por certo ainda não acabou, de transformar esse centro num policentrismo.

O policentrismo significa que o consumo, a comunicação e a cultura têm agora uma importância maior do que aquela da produção. E que, em particular o consumo, que é baseado não somente sobre shopping centers, também parques temáticos, serviços diversos, etc., desenvolve um tipo de público que não é mais o público homogêneo, massificado, da era industrial. É um público muito mais pluralizado, ou melhor, públicos. Esses públicos gostam de performar o consumo. Então, o consumo tem uma importância que mais ou menos é igual a que tinha a fábrica no passado. Para entender esse tipo de metrópole comunicacional você tem de estudar, fazer pesquisa e também transformar esses lugares do consumo, ou seja, ser também ator desses processos.

Já a comunicação na era digital reveste-se de total importância. Seja pelo aspecto produtivo, seja pelo aspecto de valores, de comportamento, pela maneira de falar, de estabelecer a relação com o corpo, e também com a identidade. A cultura como estilo de vida é cada vez mais parte constitutiva da nova metrópole. Para entender essa nova metrópole é fundamental olhar o tipo de reforma, não somente urbanística, mas dos edifícios, das lojas, e especialmente de museus, dos lugares de exposições, que tem como forma arquitetônica um tipo de desenho, mas também de uma lógica, que é póseuclidiana. Se olharmos um pouco a grande área metropolitana do mundo, esse é um desafio que é muito importante, mas difícil em algumas situações. Por exemplo, em São Paulo que é uma cidade modernista não se consegue desenvolver um tipo de arquitetura adequada à contemporaneidade. É como se a arquitetura no Brasil fosse ainda modernista, ou minimalista às vezes. E não estivesse dentro desse fluxo de desenvolver formas inovadoras, que favoreçam um tipo de percepção, de sensorialidade, e de 
comunicação que outras áreas metropolitanas favorecem. Então, esse tipo de transição significa que o território não é mais como antes. Que também a etnicidade, a sexualidade, a família, a identidade, são muito mais plurais. Tudo é muito mais possível. É raro que uma pessoa possa fazer um tipo de trabalho por toda a vida, que fique no mesmo território, que tenha a mesma família. Então isso tudo flexibiliza muito o contexto; essa flexibilidade é, para mim, parte constitutiva do conflito contemporâneo.

A metrópole comunicacional é muito mais baseada sobre o consumo e sobre a comunicação. O consumo, a comunicação e a cultura têm uma produção de valores, não só no sentido econômico, mas valores no sentido antropológico. É certo que a dimensão industrial ainda é significativa, mas não é central como era na cidade moderna. E esse cruzamento entre comunicação e tecnologia digital favorece um tipo de transformação profunda na metrópole. Na metrópole que eu chamo comunicacional, que não é mais baseada numa relação entre o Estado e a Nação. Fundamentalmente são grandes áreas metropolitanas e comunicacionais que competem e que desenvolvem estilos que favorecem esse tipo de profunda transição e que nos levam a uma ação diferente.

\section{CONSUMO PERFORMÁTICO}

O conceito de cidade é baseado numa concepção de cidadania e de produção industrial que é desafiado agora pelas novas formas de consumo. O consumo contemporâneo dos últimos anos, baseado não somente nos shopping centers, mas em um tipo de dimensão mais performática, como as performances exigidas pelos parques temáticos e restaurantes, nesses sítios desenvolvem-se um diferente tipo de relação entre a individualidade e o conceito de sociedade. Avalio também que o conceito de sociedade não é mais forte como era antes. A sociedade era muito baseada sobre a cidade. E agora se desenvolve um tipo muito mais fluido, diferenciado, também de identidade. A cidade, por exemplo, desenvolveu um tipo de identidade mais ou menos fixa; uma família, um trabalho, um território. Agora com a metrópole comunicacional, é muito mais fluida a situação, por que se tem uma multiplicidade de identidades. E isso significa também uma transformação rápida no trabalho e nas relações. Novamente, agora é difícil a pessoa fazer o mesmo trabalho por toda a vida e morar no mesmo território.

A dimensão performática é, por exemplo, quando você, na nova praça digitalizada (que corresponde a: lojas, sites informacionais, de relacionamento e de entretenimento), assim como nos shoppings, ou cinemas, no teatro, em Disney World, 
ou em parques temáticos, o público não é mais um público de espectadores, que está na frente de uma obra, que olha, escuta e depois vai embora.

É claro que essa performance passiva de olhar e ir embora ainda continua acontecendo, mas em grande parte, o que a comunicação contemporânea está favorecendo é que o público seja parte constitutiva da obra e que possa representar a sua própria história, o seu próprio conto, a sua própria imaginação. A tecnologia digital está favorecendo a criatividade, poderia favorecer a criatividade da pessoa, singular, mas também como "público", para utilizar uma palavra que é talvez atrasada. Isso significa que o público, que era somente espectador, vem agora a ser espect-ator, isto é, uma mistura daquele que participa, mas que é também ator. Espect-ator significa a coparticipação que desenvolve por meio de atitude performática no público, um espectator performático. Isto é, que não é mais passivo, mas é parte constitutiva da obra. Isso é muito claro no desenvolvimento da tecnologia digital.

Quando vamos a uma exposição de cultura digital, a uma instalação, estejamos sozinhos ou com outras pessoas, não conseguimos ficar parado, sentado, ou simplesmente olhando, precisamos participar, atuar. O corpo, no sentido também mental, é chamado a co-participar e, dessa maneira, co-produzir a obra. Esse fenômeno é muito significativo e importante. Exemplo emblemático é o que acontece no Youtube, ou mesmo nos blogs, e na internet como um todo: temos a possibilidade de gravar músicas, por exemplo, o que favorece um tipo de potencialidade participativa e criativa que não tínhamos, ou, pelo menos, essa participação era infinitamente mais reduzida.

Na cidade industrial, o público era mais compacto, mais homogêneo, até mesmo mais homologado. A potencialidade atual é favorecer um percurso individual que desenvolve um tipo de conflito contra a grande sociedade. Por exemplo, o sistema Linux ou Youtube, como vimos, tem a possibilidade de desenvolver um tipo de participação performática e auto-representativa sem precedentes. O mesmo acontece nas ruas. Produtos falsificados, isto é, falsos, são vendidos cada vez mais nas mais distintas cidades do mundo. Por exemplo, em Roma, há uma enorme quantidade de africanos que vendem produtos de griffes italianas ou francesas, por que os turistas, e às vezes também os romanos, compram. Mas por que compram? Eu acredito que muito freqüentemente todo mundo sabe que é falso. Só que esse tipo de falsificação, agora sim é "verdadeira". É difícil de perceber se um sapato Prada, ou uma bolsa Prada, é falsa ou verdadeira. Você tem de ter uma capacidade tátil, de olhar, muito, muito sofisticada. Na vida cotidiana, ao caminhar na rua, ou ir à festa, se o símbolo/logo é Prada, todo mundo pode achar que é Prada. Mas é Prada made in China ou made in Napoli. As 
pessoas que compram esses produtos compram por que uma coisa/produto que poderia ser (é) falsa pode (tem) uma capacidade comunicacional verdadeira.

Esse trânsito entre o falso e o verdadeiro é o fetichismo. O fetichismo transita nesse meio por que dá um prazer enorme à pessoa que compra um cinto Dolce \& Gabanna totalmente falso, por que ao mesmo tempo, quando ela está na rua, num night $c l u b$, aquele cinto com o símbolo $D \& G$ é totalmente verdadeiro. E o prazer é baseado num fetichismo. O fetichismo não é verdadeiro ou falso. O fetichismo é falso $\boldsymbol{e}$ verdadeiro. Então o fetichismo é a chave para misturar o que antes era separado. Isto é, verdade ou falsidade. No fetichismo, falso e verdadeiro se misturam e todo mundo fica mais ou menos feliz. Da China até o turista e uma pessoa sem recursos.

Tudo isso significa que quando falamos de espaço público, utilizamos ainda uma concepção, um conceito, uma idéia baseada na história da modernidade. A história da modernidade capitalista burguesa diferencia claramente o espaço privado da cena pública. O que notamos é que agora está acontecendo uma transição, em que o conceito de espaço público não é mais como antes. O que está acontecendo não é mais claramente interpretável na distinção dualística público-privado. Há às vezes uma expansão da privacidade num território que antes era totalmente público. E às vezes há uma expansão de um território público num lugar que era antes totalmente privado. Por exemplo, a comunicação digital é também um espaço. A tela do meu computador é um espaço e um tempo. Esse tipo de público-privado se relaciona nesse tipo de espaçotempo, tela-computer. E não é mais possível interpretar os fenômenos, que ali se manifestam, nessa dimensão dualística. Ao mesmo tempo, em alguns espaços da área metropolitana em São Paulo ou também no Rio de Janeiro, há uma tradição popular de viver justamente nesses tipos de espaços, no Rio, no espaço da cidade aberta, não somente no mar, mas na ruazinha, ou também no centro histórico, mas também nos shopping centers. Também em Salvador - essa dimensão em Salvador é ainda mais clara talvez. Salvador é uma cidade onde todo mundo pode viver no espaço público, isto é, open air, viver na área aberta. Mas o que acontece é que freqüentemente outro lugar, os shopping-centers, são os mais "participados" de vida. Então qual é o espaço público, é o shopping ou a beira do mar?

Todo mundo pode entrar no shopping center, isto é, a função que na modernidade era desenvolvida pela praça como o centro do espaço público, agora está nesses centros comerciais. Agora, também na Itália que é o país da praça, ainda é forte a maneira que as pessoas gostam de viver na praça. Mas a praça não é mais o centro do espaço público, seja na Itália, seja na Europa ou no Brasil. Em São Paulo, a praça não 
existe. O shopping center é uma mistura de público-privado, que não dá mais para utilizar a dicotomia clássica do público-privado. É como se a força semiótica, comportamental e sensual do shopping center misturasse constantemente o que era público e o que era privado.

\section{BODY-CORPSE}

A nova forma de comunicação, que é em parte baseada sobre a tecnologia digital é, certamente, o fenômeno mais forte de transformação. A comunicação desenvolve um tipo de sensibilidade do olhar e da experiência de relação com as outras pessoas, que não estão no mesmo espaço-tempo, mas estão em outro contexto, que é diferente do que ocorreu ao longo da história. Por exemplo, para falarmos de espaço-tempo, se estamos ligados na internet podemos ter uma comunicação simultânea com pessoas que podem morar em mais ou menos todos os lugares do mundo, e isso nos dá um sentido onde os conceitos de tempo e de espaço se modificam profundamente. Ao mesmo tempo, podemos nos comunicar com pessoas dessa forma, podemos olhar um jornal de Nova York, ou de Pequim, podemos escrever e-mail ou escrever no Orkut. Podemos fazer uma multiplicidade de coisas mais ou menos simultaneamente, o que antes era totalmente impossível. Isso desenvolve um tipo de capacidade e um tipo de relação entre o olhar, o cérebro e o corpo, que favorece uma multiplicação perceptiva e também cognitiva. Por isso, acredito que essa transformação é a mais significativa na contemporaneidade.

Já na modernidade, o olho é não somente uma janela que abre para o exterior, mas também um órgão que absorve na sua própria sensibilidade. Então olhar é um treino que a etnografia desenvolve profundamente. Treinar a olhar e se olhar, olhar-se. Por que não há nada de natural em olhar. O olhar é sempre culturalmente determinado. Então que olhar seja culturalmente determinado significa que agora, no contexto atual, a coisa mais significativa, seja didaticamente, seja fazendo pesquisa, é aprender, desenvolver, modificar, inventar, formas novas de olhar. Isto é, a eróptica, nas minhas palavras: uma mistura de erotismo com óptica. A eróptica mistura uma dimensão sensual, perceptiva e sensorial do olhar. E esse tipo de tecnologia digital, falando de internet, a relação entre olho, tela, mão, mouse, cérebro, corpo, é muito mais interativa do que se poderia imaginar. Não tem uma comparação que se possa fazer com a cultura analógica: na frente do cinema eu fico espectador; na frente da tela do computador, eu sou interativo, totalmente interativo. É favorecida a minha co-participação sensorial e 
multi-sensorial. E o órgão que é mais ativo sobre esse tipo de procedimento é o olho. Olhar agora tem uma capacidade de absorver, compreender, uma multiplicidade de códigos em um mesmo momento. Uma tela de um computador emana uma multidão de informações simultaneamente que o olho, o olhar - esse treino de olhar e olhar-se - tem a capacidade de absorver, entender e interagir, e às vezes modificar. Isso é característico da cultura digital. A cultura digital desenvolve uma potencialidade de olhar, olhareróptica simultaneamente, interativamente e às vezes, criativamente como nunca foi antes.

A cidade para mim é como se fosse um organismo subjetivo, vital, que absorve como uma esponja o que acontece e elabora a sua própria linguagem. Esse tipo de linguagem que a cidade, especialmente a área metropolitana, elabora, influencia profundamente o tipo de comportamento das pessoas que moram nessa área metropolitana. Por isso, seria possível dizer que a linguagem da metrópole é baseada sobre lugares, espaços, e, principalmente, sobre interstícios, isto é, um espaço que está in between, que está entre, um espaço conhecido e um desconhecido. Esses interstícios favorecem um tipo de linguagem, que é dialogicamente entrelaçado com a linguagem do corpo. E a linguagem do corpo de cada pessoa, é muito diferenciada culturalmente e comunicacionalmente, mais que sociologicamente. É mais uma auto-percepção comunicacional que diferencia essas pessoas que uma diferenciação sociológica. Esse tipo de diferenciação, baseada sobre um tipo de linguagem do corpo e o tipo de linguagem dos interstícios, permite uma dialógica nova, baseada em sincretismos culturais, "alicerçada" sobre extrema mobilidade e fluidez. Essa mobilidade, fluidez e hibridização, é parte da experiência cultural, corporal, e também urbanística, da metrópole contemporânea.

Dentro da metrópole comunicacional, é fundamental focalizar os interstícios. Os interstícios são espaços in between, zonas in between, isto é, que estão entre lugares bem conhecidos. Interstício é uma coisa flexível, mutante, flutuante. Por exemplo, os espaços das raves eram muito intersticiais. Portanto, entendemos que a metrópole contemporânea, a metrópole comunicacional, desenvolve-se muito graças também aos interstícios. E os interstícios, por sua vez, favorecem um tipo de dialógica entre um panorama de corpo, isto é, um body-scape. Utilizamos a palavra location, em inglês, para determinar um lugar-espaço-zona-interstício. Body-scape é um corpo-panorama. A dialógica da metrópole comunicacional é justamente essa interação entre interstícios flutuantes e corpos da mesma maneira flutuantes. Os dois favorecem um tipo de panorama que cruza, incorpora o que antes era separado: uma location específica de um 
corpo, assim como um corpo de interstícios. Essa dialógica, que mistura orgânico e inorgânico, corpo e coisa, ou body-corpse (Canevacci 2007), body como o corpo vivo, e corpse como o corpo morto. Então body-corpse, no hífen que separa e unifica body e corpse, acontece o trânsito, a dimensão transitiva entre corpo vivo e corpo morto que antes era clara e rigidamente separada e que agora se mistura dessa maneira transitiva.

O processo de hibridização é um processo mimético, em que um corpo assume uma parte, incorpora, hibridiza outra parte, a do interstício. Mas também o interstício, graças ao design, ao sound-scape, à música, etc, mimeticamente absorve, hibridiza, uma parte do corpo. Então, entendemos que o sincretismo pode ser definido como essa contínua mistura mimética parcial e inconciliável - o trânsito híbrido entre interstícios do corpo.

$\mathrm{Na}$ era da modernidade plena, a dimensão social do trabalho, da família, do território, era fortíssima. As pessoas tinham um mesmo trabalho por toda a vida, tinham uma família por toda a vida, etc. Agora, em particular graças às tecnologias digitais, mas não somente, esse tipo de composição social é muito menos evidente que um tipo de flutuação comunicacional. Uma pessoa pode se auto-representar de uma maneira muito mais livre e descentrada do que antes. Agora um jornalista, um pesquisador, um antropólogo, não tem mais a autoridade de representar o outro. Ele tem uma possibilidade dialógica, mas o outro se auto-representa, se auto-narra, se auto-compõe. Esse tipo de auto-representação é parte fundamental do multivíduo da metrópole comunicacional.

O conceito de indivíduo é de origem latina, que traduz uma palavra grega, isto é, atomon. Atomon é igual a indivíduo, isto é, indivisível. A-tomon, não divisível. Por que na cultura ocidental, o indivíduo é a última parcela social que não é mais possível dividir. Por que isso seria loucura, esquizofrenia ou morte. Essa concepção do indivíduo indivisível, como é atomon, é uma concepção que pertence à história da cultura ocidental, desde a Grécia e Roma, até a modernidade. Essa relação indivíduo/indivisível traz uma questão: o indivíduo tem uma identidade, isto é, ele é igual num contexto diferente. E esse é o grande desafio da cultura ocidental. A identidade ocidental é esse paradigma. Ser igual num contexto diferente. Só que, todo mundo sabe que não funciona. Nunca funcionou. Ou se funciona é apenas num domínio auto-repressivo.

O conceito de multivíduo é um conceito mais flexível, mais adequado à contemporaneidade. Por que significa que multivíduo é uma pessoa, um sujeito, que tem uma multidão de eus na própria subjetividade. O plural de eu, não é mais nós, como no passado. O plural de eu, deve ser eus. Essa constatação possibilita entender que as 
pessoas podem desenvolver uma multiplicidade de identidades, de eus - multividuo; fazer uma co-habitação flutuante de diferentes selves (plural de self) que co-habitam, às vezes conflitam ou constroem uma nova identidade, flexível e pluralizada. O indivíduo contemporâneo, que é o multivíduo, é esse tipo possibilidade. Acredito que o multivíduo seja a potencialidade conceitual mais adequada à metrópole comunicacional: uma simetria, uma dialógica, uma interatividade entre metrópole comunicacional, subjetividade multividual e cultura digital.

No passado, essa dimensão era mais interpretada num sentido de uma esquizofrenia, esquizo significa dividir. Então esse tipo de multiplicidade era esquizóide, era considerada uma loucura, uma extravagância. Essas pessoas eram os artistas, pintores, músicos, poetas. Agora, é claro que poderia haver sempre uma dimensão de frustração, mas experimentos de multiplicidades conflitantes que coabitam o mesmo eus (o artigo no singular e o pronome no plural: $o$ eus. $O$ eus tem a potencialidade de desenvolver uma pluralidade coabitativa, conflitante, mas potencialmente, não-patológica. Também a distinção entre norma e desvio, o que é normal e o que é anormal, pertence à história da psicopatologia. E muito freqüentemente a psicopatologia do passado definia a pessoa como louca por que era muito poética, muito estranha, não era possível aceitar esse tipo de multiplicidade. Com o favorecimento desse tipo e comportamento, proporcionado pela tecnologia digital deve crescer e se estabelecer.

Nessa perspectiva construtivista, nos anos 90 a partir das pesquisas sobre as culturas eXtremas (Canevacci 2005), foi possível detectar a existência de uma juventude muito móvel, muito difícil de focalizar e de interpretar. Não toda a juventude, mas uma parte da juventude estava elaborando um tipo de experiência, elaborando um tipo de desafio à política tradicional, que era muito interessante. Não era como todo mundo pensava naquela época: "os jovens são manipuladores, são homologadores, não é mais como antes. Antes sim que era a política". Esse tipo de visão super tradicional, em que a política, a beleza, a crítica, era somente possível quando eu era jovem, e que agora todo mundo é burro, idiota, homologado, é uma visão totalmente falsa. Não dá para enfrentar dessa maneira o que acontece nos dias atuais. O que estava acontecendo naquele período, por exemplo, na música eletrônica, no techno, na diferença de estilos, muito baseado no comportamento da juventude, que depois a moda replicava, mas também nas raves, eram um tipo de festa ilegal que transformou profundamente o conceito industrial. Por que as raves eram praticadas na velha área industrial, na fábrica que não funcionava mais, na fábrica aposentada. Então esse tipo de força corporal, 
também às vezes muito desesperada, mas com uma vontade de não ficar nos anos 80 ou 70, mas ir para a frente, se manifestava. Essa cultura eXtrema, identificada na pesquisa com os jovens, era baseada numa irregularidade em relação aos modelos que são mais tradicionais. Porém, o que está acontecendo agora é ainda mais complicado, por que aquele período acabou. Não é mais um momento onde um comportamento, um estilo, fica na sua dimensão crítica constantemente, mas ele se desenvolve por um período e depois se acaba. Assim, constata-se que não seja mais possível uma transformação geral, total das coisas. Há espaço sim, para pequenas transformações, fragmentos de transformações, que no momento que favorece esse tipo de mudança, libera uma enorme potencialidade energética, psicocultural e, performática.

\section{MÉTODOS POLIFÔNICOS}

No final dos anos 60, participei da luta política, trabalhando e estudando, com uma formação baseada na Escola de Frankfurt, em particular Adorno, Benjamin, Marcuse e outros. Proponho então uma digressão crítica sobre a dimensão dialética como instrumento não somente lógico de interpretação, mas também de modificação, às vezes chamada de revolução. Quando aconteceu a crise da política na Itália, e na minha visão "da política", eu fui convidado a vir ao Brasil. O convite para vir a São Paulo foi para mim um desafio enorme, por que fui levado a uma situação que era totalmente diferente da que eu tinha como embasamento filosófico, antropológico, metodológico. E nessa ocasião, a situação era, ou eu tentava defender a minha visão do mundo, de manter a minha visão da dialética, da política, ou perder-se... Então, depois de um tempo em que eu fiquei muito flutuante, não é que eu decidi, mas mais ou menos espontaneamente, eu comecei perder-me numa metrópole como São Paulo, que não era possível interpretar com os conceitos que eu tinha em Roma. Era totalmente diferente. Então eu decidi perder-me. Perder-me não somente no sentido psicogeográfico, mas perder-me no sentido teórico, conceitual, corporal. Esse foi um período para mim em grande parte de crise e em parte de uma riqueza infinita: perder-me foi uma experiência dura, mas que manifestava um enorme prazer.

Para tentar entender uma metrópole como São Paulo eu comecei a não utilizar mais o conceito de dialética, baseando-me em um novo tipo de estudo que estava fazendo naquela época, em particular com um autor heterônimo: Mikhail Bakhtin. Um autor russo muito isolado, naquela época da antiga União Soviética. Para Bakhtin o conceito de polifonia era aplicado à Dostoyevsky. A grande literatura era baseada sobre 
um monologismo. Temos um personagem principal que é o autor, não somente o autor literário, mas poderia ser também o autor antropólogo. E depois temos personagens secundários, terciários, quaternários, que eram sempre projeções do autor e do personagem. Dostoyevsky favorece uma grande revolução na construção literária por que, segundo Bakhtin, elabora um tipo de visão literária polifônica, no sentido que cada personagem tem a sua própria psicologia, o seu próprio estilo de escritura, a sua própria visão do mundo. Então não tem mais um centro, autor-herói, como era antes, mas autorherói-personagem se multiplicam nas próprias descentradas psicologias e estilo de escritura.

Esse tipo de polifonia aplicado à literatura foi para mim um instrumento fundamental para aplicar à metrópole, por que também a metrópole -São Paulo - para mim era assim. Não era uma metrópole totalizante, era polifônica. No sentido que cada pequeno fragmento da metrópole tinha uma história. Essa história do fragmento era possível se interpretar focalizando aquele fragmento sem estabelecer uma relação dialética com a totalidade, como eu teria feito antes. Por isso, para mim, A Cidade Polifônica (Canevacci 1997) foi uma aventura em que cada fragmento era analisado em si mesmo, como uma potência comunicacional própria, que aquele fragmento emanava. Depois, cada pessoa, eu primeiro, mas também um leitor pode desenvolver o seu próprio itinerário, a sua própria montagem dos fragmentos. Então a montagem dos fragmentos favorece um descentramento.

Depois desenvolvi uma metodologia baseada sobre um fetichismo metodológico, sobre a crise da taxonomia e sobre uma mistura de linguagens. O fetichismo metodológico significa que a comunicação contemporânea desenvolve cada vez mais um tipo de fetichismo que não é mais um fetichismo tradicional baseado numa visão religiosa, colonial, marxista, freudiana ou do fetichismo pornô. A comunicação digital atual, a arte, arquitetura etc., favorecem uma enorme produção de fetichismos, que são fetichismos visuais, baseados sobre mercadorias visuais. E isso significa que o fetichismo metodológico é muito baseado sobre o olhar. Fazer-se olho, fazer-se ver, que significa desenvolver uma sensibilização do olhar, dos olhares, de se olhar e de olhar, que é um treino, um exercício. Treinar-se a desenvolver uma sensibilidade sensorial e conceitual, baseada num corpo cheio de olhos. Isso é parte constitutiva do meu método etnográfico.

Essa polifonia é uma fragmentação sincrética de linguagem, que deveria favorecer a leitura poética das pessoas. Porque cada fragmento quer e deseja a sua própria metodologia. Não é mais como antes, em que você buscava a metodologia e 
aplicava o método naquele contexto. Acredito que desenvolver esse tipo de sensibilidade do olhar, esse corpo cheio de olhos, significa que cada fragmento comunicacional digital contemporâneo deseja a sua própria e única metodologia. Quando se aplica em um determinado fragmento, depois se acaba. Isto é, em parte complicado, em parte maravilhoso. Vamos pensar um exemplo prático: se eu tenho que fazer uma palestra sobre o assunto do fetichismo, antes eu poderia ler o meu ensaio por uma hora, e todo mundo ficava satisfeito, fazendo perguntas e acabava o discurso. Agora se o assunto são os fetichismos visuais, tenho de desenvolver um tipo de comunicação que mistura linguagens diferenciadas, eu nunca poderia ler um texto simplesmente. Por exemplo, uma imagem com uma escrita, com um som e com uma voz, favorece um tipo de conceitos sensoriais que mistura uma dimensão de sensorialidade com uma dimensão da racionalidade. Por que a questão profunda da contemporaneidade é que o conceito não deve ser abandonado, ou seja, jogado no lixo. O problema é que o conceito não pode ser mais baseado, como antes, sobre uma visão de uma lógica identitária fixa. O conceito agora é muito mais flutuante e, por isso, transitivo. E essa transitividade se mistura com a sensibilidade. Isto é, o dualismo clássico entre conceito e sensorialidade, corpo e mente, agora tem de se hibridizar de novo, em uma mistura multi-linguística e multi-sensorial que proporciona um entendimento diferenciado. Que não é mais baseado sobre a palavra, mas sobre "coisas múltiplas". Então, quando eu faço esse tipo de palestra, para voltar ao exemplo citado, ela poderia não ser ao mesmo tempo baseada sobre conceitos, palavras, escritas... misturadas com sons, ruídos, música, imagens, filmes e talvez performances.

\section{REFERÊNCIAS BIBLIOGRÁFICAS}

CANEVACCI, Mássimo. Una stupita fatticità. Feticismi visuali tra corpi e metropoli. Milano: Costa\&Nolan, 2007. . Culturas eXtremas. Rio de Janeiro: DpA, 2005. . A cidade polifonica. Ensaio sobre a antropologia da comunicação urbana., São Paulo: Studio Nobel, 1997.

Artigo recebido em 13/3/2009.

Aprovado em 30/4/2009. 